\title{
A IMPRENSA, O CONSUMO (DE INFORMAÇÃO, INCLUSIVE) E O FETICHE DA TECNOLOGIA
}

\author{
Media, consumption (also of information) and the fetishism of \\ technology
}

\author{
La prensa, el consumo (de información, inclusive) y el fetiche \\ de la tecnología
}

\section{Eugênio Bucci}

Professor associado do Departamento de Jornalismo e Editoração da ECA-USP, onde dá aulas de graduação e pós-graduação (no PPGCOM, Ciências da Comunicação). É conselheiro do Institutos de Estudos Avançados da USP e superintendente de Comunicação Social da USP. É integrante do grupo de pesquisa "Jornalismo, Direito E Liberdade", vinculado ao Instituto de Estudos Avançados e à ECA-USP.

E-mal: ebucci@usp.br

RESUMO Este artigo encerra uma reflexão teórica com o objetivo de tematizar o impacto das novas tecnologias na percepção de profissionais, usuários e pesquisadores de jornalismo, publicidade e comunicação social de modo mais amplo. Localizando pontos de conexão entre o universo da imprensa e a sociedade de consumo, mediada por técnicas comunicacionais específicas da publicidade e mesmo das relações públicas, o texto recupera na história recente depoimentos de pensadores sobre o advento de mudanças disruptivas, com o objetivo de mostrar que: (1) a sensação de que as coisas nunca mudaram tão depressa data pelo menos de alguns séculos; e (2) é preciso prudência para não idolatrar as inovações da técnica como se fossem o útero do futuro.

PALAVRAS-CHAVE Jornalismo, Consumo, Tecnologia, Informação, Democracia.

\begin{abstract}
This paper thematizes the impact of new technologies on the perception of professionals, users and researchers of Journalism, Advertising and Media. Finding connections between the media and consumer society, mediated by specific communicational techniques of advertising and public relations, this paper collects some testimonials about the advent of disruptive changes, aiming to prove that: (1) the feeling that things have never changed so quickly dates at least from a few centuries ago; and (2) it is necessary to be careful and not to idolize technical innovations as if they were the womb of the future.
\end{abstract}

KEYWORDS Journalism, Consumer, Technology, Information, Democracy.

RESUMEN Este artículo contiene una reflexión teórica con el objetivo de poner en primer plano el impacto de las nuevas tecnologías en la percepción de los profesionales, usuarios e investigadores del periodismo, la publicidad y los medios de comunicación en general. Encontrar puntos de conexión entre el mundo de los medios de comunicación y la sociedad de consumo, mediada por técnicas de comunicación específicas de la publicidad e de las relaciones públicas, el texto recupera testimonios de pensadores sobre el advenimiento de cambios disruptivos, con el fin de demostrar que : (1) la sensación de que las cosas no han cambiado tan rápidamente la fecha, al menos, un par de siglos; y (2) que es necesaria la precaución de no idolatrar a las innovaciones técnicas como si fueran el vientre del futuro.

PALABRAS CLAVE Periodismo, Consumidor, Tecnología, Información, Democracia.

Este texto baseia-se em uma aula do autor na abertura da disciplina Jornalismo digital, oferecida no primeiro semestre de 2010 na ECA-USP. Paula Sacchetta, Daiane Domingues, Márcia Scapaticio e Marcos Ritel, alunos da disciplina, trabalharam na transcrição e na primeira edição do texto. Também compareceu à confecção do presente artigo a pesquisa bibliográfica realizada pelo autor para a conferência "O rumor da mídia", publicada na forma de ensaio em: NOVAES, A. (Org.). Mutações: o silêncio e a prosa do mundo. São Paulo: Edições Sesc São Paulo, 2014. v. 1, p. 167-192. 
Eia! eia! eia!

Eia electricidade, nervos doentes da Matéria!

Eia telegrafia-sem-fios, simpatia metálica do Inconsciente!

Eia túneis, eia canais, Panamá, Kiel, Suez!

Eia todo o passado dentro do presente!

Eia todo o futuro já dentro de nós! eia!

Eia! eia! eia!

Frutos de ferro e útil da árvore-fábrica cosmopolita!

Eia! eia! eia! eia-hô-ô-ô!

Nem sei que existo para dentro. Giro, rodeio, engenho-me.

Engatam-me em todos os comboios.

Içam-me em todos os cais.

Giro dentro das hélices de todos os navios.

Eia! eia-hô! eia!

Eia! sou o calor mecânico e a electricidade!

(Álvaro de Campos, “Ode triunfal”)

Um lugar comum dos nossos dias é a crença de que as gerações presentes são as mais expostas a uma presumida revolução tecnológica. Nunca se viram tantos equipamentos novos como agora. Nunca se falou tanto em máquinas, softwares, hardwares, bits e mudanças disruptivas de hábito. Seríamos nós os protagonistas da maior transformação técnica de todos os tempos.

Este artigo parte da desconfiança de que, sem prejuízo do aumento da intensidade e da velocidade das inovações e, em boa medida, das mutações por que passamos, essa sensação de que nós é que estamos embarcados nas transformações não passa de uma... sensação. Não é raro que o olho humano festeje os avanços da técnica. Não é raro a embriaguez do corpo quando se vê transportado a outro mundo pelos fios da ciência. Não é raro - e não é de hoje. Um olho no passado não seria de todo mau. Nossos antepassados experimentaram, há bem uns duzentos, trezentos anos, a mesmíssima... sensação.

Comecemos por lembrar a célebre passagem de Walter Benjamin (1986, p. 226):

Há um quadro de [Paul] Klee que se chama Angelus Novus. Representa um anjo que parece querer afastar-se de algo que ele encara fixamente. Seus olhos estão escancarados, sua boca dilatada, suas asas abertas. O anjo da história deve ter esse aspecto. Seu rosto está dirigido para o passado. Onde nós vemos uma cadeia de acontecimentos, ele vê uma catástrofe única, que acumula incansavelmente ruína sobre ruína e as dispersa a nossos pés. Ele gostaria de deter-se para acordar os mortos e juntar os fragmentos. Mas uma tempestade sopra do paraíso e prende-se em suas asas com tanta força que ele não pode mais fechá-las. Essa tempestade o impele irresistivelmente para o futuro, ao qual ele vira as costas, enquanto o amontoado de ruínas cresce até o céu. Essa tempestade é o que chamamos progresso. 
O que se quer dizer aqui é que o tempo todo, e isso desde muito tempo, o humano se sente soprado por uma ventania, sempre impelido para a frente, mas sempre com os olhos no passado. Sempre o progresso o assusta, como a fúria de uma tempestade fora de si, tão selvagem quanto cruel. Não obstante, a humanidade, vítima da tempestade, é também a agente da tempestade. O progresso a apavora e a leva adiante, como se a levasse de costas para um lugar desconhecido. A matéria dessa tempestade, a substância que se abate sobre o anjo e o impede de fechar as asas, a força material que o empurra para o futuro, chama-se tecnologia.

Em nenhum outro lugar essa sensação é tão presente como no mundo da comunicação - há um bom tempo. Nenhuma outra área sofreu tanto o impacto da tecnociência, e, desde o limiar do século XX, nenhuma desempregou e reempregou tanta gente com tanta rapidez. Em nenhuma as fusões empresariais envolveram cifras que cresceram em curvas tão ascendentes. Em nenhuma as pessoas se sentiram tantas vezes "sem chão" como na indústria do entretenimento, nos complexos midiáticos, nos oligopólios que liquefazem num mesmo caldo gigantes da telefonia, da indústria fonográfica, das relações públicas, do cinema, da indústria de games, da publicidade, do jornalismo. Ninguém como nós, que aqui estamos, nós que mexemos com esse assunto, experimenta com tanta carga a sensação de viajar na velocidade da luz em meio a um vento solar na direção de um universo escuro.

A verdade é que as inovações tecnológicas nas comunicações sempre assustaram e, também, fascinaram. Sempre imobilizaram e eletrizaram. Para os profissionais e pesquisadores, sempre sinalizaram o fim dos tempos, embora, dos tempos, sejam apenas o começo. Por isso, refletir um pouco sobre o choque das tecnologias no pensamento dos que tiveram olhos para as comunicações talvez aclare um pouco o passado, e simplifique um pouco a sombra do futuro.

Mas a tecnologia, se concentra peso e matéria sobre as asas do anjo, não é a força histórica que move o mundo. O capital, em sua voragem de acumulação e reprodução sem freios, apodera-se das inovações tecnológicas e reduz o tempo de seu ciclo a intervalos que diminuem e se comprimem em escala exponencial.

Ou idolatramos ou amaldiçoamos a tecnologia, sem nexo com o processo histórico. O desvio mais comum entre nós talvez seja nem tanto amaldiçoar, mas embarcar no deslumbramento acrítico em relação a chips que vendem soluções para problemas que não existem e sínteses para contradições imaginárias.

Pense-se, por exemplo, no jornalismo on-line, na era digital e nas redes interconectadas. As maravilhas eletrônicas fulguram como inventoras de um novo alvorecer de liberdades jamais imaginadas - e paradoxalmente aprisionam a imaginação dentro de seus paradigmas labirínticos. Ocorre que a função do jornalismo não foi inventada pela tecnologia, mas pelas relações entre cidadãos. As ferramentas estendem o alcance dos procedimentos jornalísticos e abrem novas pontes entre os sujeitos, possibilitando um jornalismo cujas fontes são as multidões. As tecnologias não inventam; a condução da mudança ainda está no sujeito portador do discurso jornalístico. Isso é fundamental porque tem sido muito comum a visão de revolução, de mudança total causada exclusivamente pela tecnologia. E se essa mirada se equivoca quando tem em foco o jornalismo, ela se equivoca também quando se expande no horizonte das "relações públicas generalizadas", para 
usar aqui a expressão de Bernard Miège, essa idade da imprensa em que a publicidade, os relatos informativos, os debates públicos e as comunicações para o consumo se entrelaçam a ponto de quase se fundirem numa grande arena global. ${ }^{1}$

As relações democráticas e a fiscalização do poder pelo conjunto da sociedade, alicerçada pelo direito do cidadão a informação e comunicação, predominam sobre os feitos da tecnologia em fundar a razão de ser da imprensa - e dos desdobramentos que ela nos veio legar, como a indústria da publicidade. Essas práticas já vinham de antes e prosseguem enriquecidas por novas possibilidades. O formato que a instituição da imprensa ganhou a partir do advento da democracia exige que a sociedade sustente a função do jornalista independente. No modelo dos jornais clássicos, a receita que os sustenta vem em parte do público, que compra um exemplar ou faz uma assinatura, e outra parte vem da publicidade, que compra espaço numa relação de confiança que o público tem com o jornalista, já previamente dada nesse vínculo que sustenta a redação. Supor a figura de um jornalista que fiscalize o poder, que faça perguntas em nome do cidadão, é supor o modelo em que esse cidadão sustenta esse jornalista.

A Internet não liquida o jornalismo, embora o modifique de alto a baixo. De início, o jornalismo on-line aproximou-se do modelo da radiodifusão, cuja veiculação é aparentemente gratuita e a receita origina-se apenas da publicidade. Hoje, os formatos se diversificam. A receita da venda de assinaturas on-line, para serviços puramente digitais, sem mais papel, ganhou prevalência sobre títulos internacionais consagrados da "velha mídia", como The New York Times ou Washington Post. A comercialização de conteúdos ganha inúmeras conjunções até então inviáveis, assim como a própria prática do jornalismo colaborativo, propiciada pelas tecnologias digitais, enriquecidas pelas técnicas de jornalismo de dados e pelos progressos da reportagem assistida por computador (RAC). ${ }^{2}$ Enfim, as novas tecnologias, sem prejuízo de seu empuxo disruptivo, reconciliam-se com a vocação original da imprensa na democracia, abrindo a ela novas trilhas de fiscalizar o poder e promover o diálogo crítico entre os cidadãos.

Temos de olhar sempre o fenômeno da tecnologia como algo que vem somar às relações sociais previamente postas e que se prolongam para além do seu advento. Evidentemente não é Gutenberg que inventa o livro. É claro que ele propicia técnicas que permitem sua difusão, e isso muda a própria natureza do conceito de livro. Mas ele não o inventa, apenas o redefine.

Assim também a câmera fotográfica não inventa a perspectiva artificialis, já adotada por pintores antes de seu surgimento. Desde o Renascimento, em parte por influência de Leonardo da Vinci, pintores se valiam de uma grande caixa de madeira (a câmera escura) - que, a partir de um orifício em uma de suas faixas, "projetava” imagens na face oposta, para copiar retratos da nobreza. O pintor holandês Johannes Vermeer (1632-1675) foi outro que empregou bastante a câmara escura. Quer dizer: a fotografia apenas providenciou o suporte químico onde antes atuavam os pincéis do artista.

1. A propósito, consultar Miège (1995).

2. Ver Demeneck (2016). 
De modo análogo, a tecnologia da era digital não inventa um novo jornalismo, apenas permite que pessoas, por meio dela, exercitem possibilidades que não estavam abertas. A necessidade democrática das redações independentes e da fiscalização do poder já existia, e prossegue atual. Eis o primeiro alerta: entrar nesse universo deve significar entrar criticamente nesse assunto. Em lugar de ficar de joelhos perante a tecnologia, o pesquisador existe também para questioná-la. Essa atitude é tanto mais preciosa quanto mais ganhamos consciência de que, como já foi dito, da indústria gráfica que assegurou a expansão dos jornais diários - nesse caso, a indústria conjugada com a extensão das ferrovias, essenciais para a distribuição, e com a entrada da publicidade nos diários, o que ajudou a reduzir o preço dos exemplares para os leitores finais - decorreram as outras modalidades da comunicação social que hoje ocupam cada centímetro quadrado dos territórios do planeta e cada centímetro cúbico do ar atmosférico. Em resumo, quando olhamos para a relação entre imprensa e tecnologia, estamos olhando, de fato, para as relações entre tecnologia e todas as dimensões da comunicação social e do consumo de informação e bens.

A associação entre o mundo do consumo e o universo da comunicação - cujo embrião é a imprensa - não é arbitrária, mas histórica e, em boa medida, natural. A revolução industrial - cujos efeitos e causas se entrecruzam com as revoluções democráticas, a invenção do Estado moderno e sua burocracia e o crescimento dos mercados - engendra uma sociedade integrada pelas comunicações e pelo consumo, primeiro no âmbito das nações segundo suas fronteiras idiomáticas, e depois no âmbito planetário. Estudiosos como Nestor Garcia Canclini veem na dimensão do consumo algumas das soluções antes circunscritas aos domínios da cidadania. Alguns de seus apontamentos já são bem conhecidos.

Homens e mulheres percebem que muitas das perguntas próprias dos cidadãos - a que lugar pertenço e que direitos isso me dá, como posso me informar, quem representa meus interesses - recebem suas respostas mais através do consumo privado de bens e dos meios de comunicação de massa do que das regras abstratas da democracia ou pela participação coletiva em espaços públicos. (Canclini, 1995, p. 30)

O belga Derrick de Kerckhove, considerado um dos principais herdeiros do legado teórico de Marshall McLuhan, que vive no Canadá e frequentemente vem ao Brasil para ministrar palestras, expôs em uma conferência na Aberje, em São Paulo, uma síntese dos saltos tecnológicos que afetaram as comunicações. ${ }^{3}$ Segundo ele, há 1.700 gerações passadas, o homem moderno começou a desenvolver a linguagem. Há 300 gerações, esse homem desenvolveu a escrita; há 35, desenvolveu a impressão, com a máquina de Gutenberg. Mas até isso é perigoso. Até o estabelecimento desse marco, dessa linha divisória, é discutível, pois há registros de atividades similares a edição de imagens na China, bem antes disso, por exemplo. O que conta aqui é que a chamada civilização ocidental encontra um emprego social para o livro ou texto impresso. Porém isso acontece há apenas 35 gerações.

3. Nascido na Bélgica, doutor em sociologia da arte e literatura francesa, Kerckhove foi diretor do Programa McLuhan em Cultura e Tecnologia da Universidade de Toronto. Sua palestra na Associação Brasileira de Comunicação Empresarial (Aberje), em São Paulo, foi em 9 de novembro de 2007. 
O que vem depois é muito rápido. Aproximadamente em 1910, o telégrafo se espalha; em 1925, mais ou menos, o telefone e o filme mudo entram na rotina das sociedades desenvolvidas; por volta de 1940, o rádio e o filme falado incorporam-se ao cotidiano das comunicações; em 1955, a televisão é um eletrodoméstico mundial e os chamados meios de comunicação de massa se instalam em definitivo. Em 1985, surge o VT, e a partir dos anos 2000 já estávamos todos na Web.

Agora alguns celebram a era do Big Data, que reduziu o velho database marketing, com aqueles inventários sobre hábitos e preferências dos clientes, a futilidades. O Big Data é o database marketing sem limites. Com ele, os algoritmos e as CPUs interconectadas aprenderam a ler em profundidade os sentidos superpostos das mais efêmeras e tolas mensagens em trânsito, aprenderam a identificar motivações de cada usuário e tornaram possível aos laboratórios de exames clínicos e às empresas de seguro médico prever quando um sujeito saudável será internado numa UTI. A privacidade foi para o ralo. ${ }^{4}$

Os números dessa miríade tecnológica deixam os jornais do limiar do século XX na pré-história. A Biblioteca do Congresso Norte-Americano - que, sozinha, é maior que uma coleção inteira do New York Times, do World (do magnata Joseph Pulitzer) e de todos os jornais que circulavam em Nova York há cem anos - cabe, inteira, em apenas 385 terabytes (um terabyte é um gigabyte multiplicado por mil). Um terabyte multiplicado por mil é um petabyte - e em 1,5 petabyte podem-se guardar todas as músicas existentes no mundo.

Em apenas 10 petabytes cabem todos os conteúdos enviados pela humanidade num único dia. Numa estimativa de 2013, o Google, que lida com muito mais do que isso, processa, diariamente, 24 petabytes. Num único dia, entra em circulação um volume de mensagens que não caberia em séculos e séculos de todos os diários norte-americanos de 1900. Segundo esse mesmo levantamento, até 1986 tudo o que a humanidade conseguia guardar de informação cabia em 3 exabytes (que equivale a mil petabytes). Em 2013, a humanidade gerava 2,5 exabytes de informação num único dia.

Mil exabytes equivalem a um zetabyte - e, com 1,8 zetabyte, podemse armazenar os dados acumulados pelo planeta ao longo de um ano. ${ }^{5}$ Segundo estimativas difundidas em $2013,{ }^{6}$ o número de usuários da Internet no mundo giraria em torno de 2,6 bilhões (número que, imaginava-se, dobraria na década seguinte). A cada minuto de 2013, essa multidão disparava 168 milhões de e-mails, assistia a 1,3 milhão de vídeos no YouTube e fazia 370 mil chamadas no Skype. Atenção: isso a cada 60 segundos.

Mesmo diante dessas assombrosas cifras, devemos estar atentos a outro equívoco comum: a afirmação recorrente de que a Internet é um meio de comunicação. Isso é falso. A Internet possibilita que os meios convivam dentro de um universo virtual, mas não é um meio de comunicação. Sequer é um recipiente contendo vários meios. É, antes,

4. Ver Ullman (2013).

5. Ver reportagem de Petry (2013).

6. Dados apresentados na conferência "Impactos das redes sociais nos negócios e na sociedade”, proferida pelo colunista da Folha de S. Paulo e professor da ECA-USP Luli Radafhrer, em reunião do Conselho Consultivo da Aberje, em São Paulo, no dia 25 de setembro de 2013. 
um complexo de comunicações, relações de troca comerciais, nódulos de feixes contendo comandos financeiros, enfim, ela emula as relações sociais em outro plano, e está para a comunicação humana como a energia elétrica esteve para o modo de vida gerado pela revolução industrial que alcançou o século XX. Um portal na Internet pode ter televisão, texto, áudio e outras linguagens - todas convivendo, mais ou menos, como num jornal o fazem a infografia, o artigo de opinião, a reportagem, os quadrinhos e a crônica.

A Internet é um ambiente que expande as relações humanas, conforme McLuhan tinha previsto (veremos isso logo mais). Dentro da Internet podem estar o correio, o banco, a agência de turismo, o supermercado, a companhia telefônica, a biblioteca... Como então chamar isso de "meio de comunicação"? A Internet não se encaixa no conceito tradicional de meio de comunicação, assim como a energia elétrica não cabia no conceito tradicional do lampião a gás. O futuro não cabe nas categorias do passado - e ainda bem.

Aliás, nessa nossa volta ao passado, recuemos um pouco mais. Não é de hoje, como já foi dito, que o futuro fascina os comentaristas.

Já não dispomos de jornais para cada período do dia! Tudo quanto alguém faz e empreende, tudo o que escreva ou até mesmo planeje escrever, é lançado para as mãos do público. (...) As notícias correm de casa em casa, de cidade em cidade, de um país a outro e, por fim, de um continente ao seguinte, tudo sob a égide da pressa e da velocidade. (Goethe, 1829, apud Fonseca, 2008, p. 301)

A ansiedade que Goethe descreve já se encontrava instalada em seu tempo; era uma realidade corriqueira. Pelo menos um século antes, quando ainda não havia nada parecido com a imprensa profissional, já existiam meios para os cidadãos publicarem suas ideias ou criações artísticas. Por volta de 1830, isso poderia ser feito sem muita demora. "A égide da pressa e da velocidade" já ditava a circulação das notícias, cujo ritmo em progressiva aceleração seguiria espantando as gerações seguintes.

A imprensa virava a instituição da moda, mais rápida que outras que vinham tomando conta do pensamento, como a Igreja Católica. Ao oferecer ao homem moderno sua dose diária de informação e opinião, os jornais começavam a ocupar o lugar da Igreja. As homilias perdiam espaço para os editoriais. O francês Victor Hugo anotou: "A imprensa matará a igreja”". O filósofo alemão Georg Wilhelm Friedrich Hegel (que chegou a dirigir um jornal em Bamberg, o Bamberger Zeitung, de 1807 a 1808) disse que a leitura diária de jornais seria a oração matinal do homem moderno (1974, p. 360).

Os jornais - embriões do que hoje aprendemos a chamar grosseiramente de "mídia" - conquistavam territórios no imaginário. Joseph Pulitzer (1904, p. 28-29) deu bem a medida das sensações. "Estamos todos embarcados, queiramos ou não, numa era que

7. Giannetti observa, em nota de rodapé, que, "no início do século XIX, quando o poeta escreveu essas linhas, existiam na Alemanha um jornal matutino (publicado em Stuttgart), dois vespertinos (Hanover e Dresden) e um jornal da noite (Braunschweig)”.

8. Hugo (2016, p. 171). No mesmo trecho, diz o texto: “... o livro de pedra, tão sólido e tão durável, daria lugar ao livro de papel, mais sólido e mais durável ainda”. A citação de Victor Hugo foi anotada por Cunha (2013, p. 86). 
revoluciona o pensamento e a própria vida”, escreveu, em texto que preconizou a criação de um curso de alto nível para formar profissionais de imprensa. "O progresso caminha velozmente, com imensa aceleração, percorrendo em décadas os avanços que antes custariam séculos ou milênios."

O mesmo fascínio fez-se sentir no Brasil. Olavo Bilac (1904), encantado com novas máquinas audiovisuais, redigiu um parágrafo que hoje parece uma profecia dos telejornais com meio século de antecedência.

Justamente agora, nos últimos dias de 1903, dois físicos franceses, Gaumon e Decaux, acabam de achar uma engenhosa combinação do fonógrafo e do cinematógrafo - o cronófono -, que talvez ainda venha a revolucionar a indústria da imprensa diária e periódica. Diante do aparelho, uma pessoa pronuncia um discurso: o cronófono recebe e guarda esse discurso e, daí a pouco, não somente repete todas as suas frases, como reproduz, sobre uma tela branca, a figura do orador, a sua fisionomia, os seus gestos, a expressão da sua face, a mobilidade dos seus olhos e dos seus lábios. Talvez o jornal do futuro seja uma aplicação dessa descoberta. ${ }^{9}$

Voltando a Benjamin, ainda nos anos 1930, há outra premonição espantosa, quando ele se achava às voltas com a reflexão sobre o que sucederia com a obra de arte passível de ser reproduzida tecnicamente.

Cada pessoa, hoje em dia, pode reivindicar o direito de ser filmado. Esse fenômeno pode ser ilustrado pela situação histórica dos escritores em nossos dias. Durante séculos, houve uma separação rígida entre o pequeno número de escritores e um grande número de leitores. No fim do século passado, a situação começou a modificarse. Com a ampliação gigantesca da imprensa, colocando à disposição dos leitores quantidade cada vez maior de órgãos políticos, religiosos, científicos, profissionais e regionais, um número crescente de leitores começou a escrever, a princípio esporadicamente. No início, essa possibilidade limitou-se à publicação de sua correspondência na seção "Cartas aos leitores”. Hoje, raros são os europeus inseridos no processo de trabalho que em princípio não tenham uma ocasião qualquer para publicar um episódio de sua vida profissional, uma reclamação ou uma reportagem. Com isso, a diferença essencial entre autor e público está a ponto de desaparecer. Ela se transforma numa diferença funcional e contingente. A cada instante, o leitor está pronto a converter-se num escritor. (Benjamin, 1987, p. 183-184) ${ }^{10}$

Pouco menos de trinta anos depois, Marshall McLuhan, em 1962, foi tocado pelo mesmo rumor e antecipou o que viria a ser a Internet em geral e a Wikipédia em particular:

O próximo meio, qualquer que seja ele, deverá ser a extensão da consciência. Ele incluirá televisão como seu conteúdo, não como seu ambiente, e vai transformar a televisão numa forma de arte. Um computador como ferramenta de pesquisa e de comunicação poderia reforçar as possibilidades de busca, tornar obsoletas as bibliotecas

9. O texto foi recentemente divulgado após pesquisa de Vladimir Sacchetta.

10. O trecho foi lembrado ao autor deste ensaio pela leitura de Cunha (2013). 
convencionais, suprir as funções de enciclopédia e entregar dados personalizados em alta velocidade. ${ }^{11}$

A sensação de que a realidade se revolve em mudanças cada vez mais intensas, profundas e velozes - rápidas demais diante da capacidade humana de compreendê-las - ronda o imaginário há pelo menos dois séculos. Entre tantos que falaram disso, é de se destacar o caso de dois jovens, um com 30 anos e o outro com 28, que escreveram um trecho que ainda hoje comove pela contundência e, ao mesmo tempo, pela delicada precisão.

A burguesia não pode existir sem revolucionar constantemente os instrumentos de produção, portanto as relações de produção, e por conseguinte todas as relações sociais. (...) A transformação contínua da produção, o abalo incessante de todo o sistema social, a insegurança e o movimento permanentes distinguem a época burguesa de todas as demais. As relações rígidas e enferrujadas, com suas representações e concepções tradicionais, são dissolvidas, e as mais recentes tornam-se antiquadas antes que se consolidem. Tudo o que era sólido desmancha no ar, tudo que era sagrado é profanado. (Reis Filho, 1998, p. 11)

Os dois jovens eram Karl Marx e Friedrich Engels, autores do Manifesto Comunista, lançado em 1848. E, se quiséssemos, poderíamos voltar até Camões, sem risco de erro nenhum, já que ele também pressentia a mesma vaga de expansões marítimas e mercantis que desaguariam no capitalismo que aí está: “Todo o mundo é composto de mudança, Tomando sempre novas qualidades”. ${ }^{12}$

Lancemos mão, portanto, das mudanças. Mais ainda, lancemos mão das novas tecnologias, sem idolatrá-las como a mãe múltipla do futuro - coisa que nenhuma é, a menos que reduzamos o logos à técnica, a razão à máquina e o discurso ao objeto. Se o futuro que desenhamos é democrático, o discurso, o logos, há de vir da instituição da imprensa, germe de toda a comunicação social - e interpessoal também - que hoje pulsa. Sejamos uma excursão deslumbrada numa feira de gadgets.

Como já resultou evidente, estamos falando de fetiche - não exatamente da mercadoria, mas da tecnologia, que se põe como logos e também como ideologia autônoma.

O fetiche da mercadoria, segundo Marx, é o que encobre sua condição de trabalho alienado, aquilo que faz da mercadoria um objeto de idolatria de tal forma que sua origem social fique obscurecida. ${ }^{13}$ O fetiche completa a alienação do trabalho, funcionando como um sistema de adoração que promove o esquecimento - fazendo que o sujeito deseje o que lhe foi alienado.

O misterioso da forma mercadoria consiste simplesmente no fato de que ela reflete aos homens as características sociais do

11. A frase consta da primeira versão de Understanding Media, de 1962, conforme foi afirmado por Derrick de Kerckhove (2011, p. 10).

12. Do soneto "Mudam-se os tempos, mudam-se as vontades".

13. As considerações sobre o fetiche da mercadoria, no presente ensaio, incorporam considerações apresentadas pela primeira vez na tese de doutorado do autor: Bucci (2002). 
seu próprio trabalho como características objetivas dos próprios produtos de trabalho, como propriedades sociais dessas coisas e, por isso, também reflete a relação social dos produtores com o trabalho total como uma relação social existente fora deles, entre objetos. Por meio desse quiproquó os produtos do trabalho se tornam mercadorias, coisas físicas metafísicas sociais. Assim, a impressão luminosa de uma coisa sobre o nervo ótico não se apresenta como uma excitação subjetiva do próprio nervo, mas como forma objetiva de uma coisa fora do olho. ${ }^{14}$ Mas, no ato de ver, a luz se projeta realmente a partir de uma coisa, o objeto externo, para outra, o olho. É uma relação física entre coisas físicas. Porém, a forma mercadoria e a relação de valor dos produtos de trabalho, na qual ele se representa, não têm que ver absolutamente nada com sua natureza física e com as relações materiais que daí se originam. Não é mais nada que determina a relação social entre os próprios homens que para eles aqui a assume a forma fantasmagórica de uma relação entre coisas. Por isso, para encontrar uma analogia, temos de nos deslocar à região nebulosa do mundo da religião. Aqui, os produtos do cérebro humano parecem dotados de vida própria, figuras autônomas, que mantêm relações entre si e com os homens. Assim, no mundo das mercadorias, acontece com os produtos da mão humana. Isso eu chamo o fetichismo que adere aos produtos de trabalho, tão logo são produzidos como mercadorias, e que, por isso, é inseparável da produção de mercadorias. (Marx, 1985, p. 71, grifo nosso)

No caso da tecnologia, o sujeito, ao desejar aquilo que lhe foi alienado, deseja nesse objeto, a tecnologia, o saber que lhe foi alienado sobre seu próprio destino. Slavoj Zizek (1996, p. 25) comenta a passagem citada aqui de $O$ Capital: "Por que Marx escolhe justamente o termo fetichismo para designar a 'fantasia teológica' do universo da mercadoria?”, pergunta-se.

O que se deve ter em mente, aqui, é que "fetichismo" é um termo religioso para designar a idolatria "falsa" (anterior), em contraste com a crença verdadeira (atual): para os judeus, o fetiche é o Bezerro de Ouro; para um partidário do espiritualismo puro, fetichismo designa a superstição "primitiva", o medo de fantasmas e outras aparições espectrais etc. E a questão, em Marx, é que o universo da mercadoria proporciona o elemento fetichista necessário à espiritualidade "oficial": é bem possível que a ideologia "oficial" de nossa sociedade seja o espiritualismo cristão, mas sua base real não é outra senão a idolatria do Bezerro de Ouro, o dinheiro. (Idem, ibidem)

O fetiche é o que reveste a mercadoria da condição de objeto desejável, encobrindo, por assim dizer, a violência extrema que nele está contida. Podemos dizer, por extensão, que o fetiche que recobre a tecnologia seria um superfetiche, que a recobre da condição de saber desejável, de domínio desejável sobre o destino.

O fetiche afasta do sujeito a memória da falta e põe no lugar a visão daquilo que o completa imaginariamente, autorizando, dessa forma, a adoração do dinheiro sem requerer que essa adoração seja declarada. O fetichismo em Marx é a visão, ainda num estágio primário, da

14. Note-se como Marx descreve aqui o processo imaginário pelo qual o sujeito conhece a mercadoria. 
representação ideológica da mercadoria - ideológica, no entanto, como simples máscara da matéria.

O fetiche da mercadoria deve ser entendido hoje não propriamente como fantasmagoria, ainda que possa legitimamente em $O$ Capital ser visto como um efeito fantasmagórico. Deve ser entendido como a representação imaginária da mercadoria, constituindo sua estética. O fetiche confere uma "aura" sintética à mercadoria. A materialidade da mercadoria, portanto, não se desprende de sua representação imaginária, mas nela necessariamente se completa. Que a imagem da mercadoria concorra para negar a alienação do trabalho aí contida não constitui uma separação da imagem em relação à materialidade da mercadoria, mas constitui sua materialidade invertida: a alienação do trabalho se manifesta como objeto do desejo. A imagem da mercadoria, como a mercadoria pura (se ela existisse nesses termos, fora da linguagem), encerra sua contradição original.

Pode-se dizer que o que é socialmente fabricado não é propriamente a mercadoria, mas seu fetiche. Ao ser fabricado, o fetiche deve ser visto também como mercadoria: assim como a estética da mercadoria deve ser entendida como uma segunda mercadoria sobre a mercadoria.

Por fim, há de se salientar que o fetiche é uma noção tanto marxista quanto freudiana. É o que diz Maria Rita Kehl:

Se estivermos de acordo com Marx, o fetichismo como modo de ocultamento das relações de dominação/exploração entre os homens nasceu com ele, isto é: nasceu com a transformação dos produtos do trabalho humano em mercadorias. (...) De acordo com Freud, o fetichismo como modo de ocultamento da falta nasce com a recusa, por parte do sujeito moderno (que é o sujeito neurótico), em admitir a diferença sexual entre homens e mulheres. (Kehl, 1999, p. 86)

As mercadorias erotizam-se na mesma chave em que os objetos para o "sujeito neurótico" fetichizam-se.

O sujeito busca na mercadoria o significado que já não encontra em si. E a "aura" sintética da mercadoria, no instante do consumo, desliza para o sujeito, tornando-o seu próprio significado. Nessa perspectiva, consumir é ser consumido por aquilo que, na imagem (aurática) da mercadoria tem força significante.

É assim que o fetiche ultrapotente da tecnologia deforma a percepção que dela acalentam aqueles que operam a comunicação. As soluções apresentadas para os problemas da comunicação devem "parecer" tecnológicas mais do que ser lógicas. O logos da técnica sobrepõe-se ao da razão.

Fora isso, há um logos no jornalismo, desde que saibamos vê-lo como ética - e desse logos florescem outros, dos muitos segmentos da comunicação contemporânea, seja da publicidade, da Internet ou das redes sociais. No fundo, a inovação que interessa não vem da eletrônica, mas do aprofundamento da eficácia social da instituição da imprensa e de suas comunicações irmãs. É possível fiscalizar mais o poder? É possível integrar mais as comunidades? É possível fazer respeitar mais e mais os direitos do cidadão e do consumidor? É possível servir com mais eficiência e rapidez o público? É possível ouvir melhor o público? É possível atribuir ao público poder de produzir conteúdo? É disso que se trata. 
Mediação independente, multiplicar e melhorar os processos comunicacionais, abrir novas vias de acesso à informação, habilitar o cidadão para ser emissor de conteúdos, assegurar mecanismos de verificação e vigiar o poder. E atenção: onde a tecnologia fala em interatividade, o jornalismo e as organizações informativas falam em diálogo. Se a tecnologia pode projetar-se ao nível de enunciadora de um discurso, esse discurso não contém, não resolve e não substitui a práxis do jornalismo e da comunicação social em bases próprias da civilização e da garantia dos direitos fundamentais do cidadão, cuja inovação decorre da radicalização de sua razão democrática de existência.

\section{REFERÊNCIAS}

BENJAMIN, W. IX tese sobre a filosofia da história. In: Obras escolhidas, vol. 1: Magia e técnica, arte e política. Ensaios sobre literatura e história da cultura. Trad. Sérgio Paulo Rouanet. São Paulo: Brasiliense, 1987. p. 222-232

BILAC, O. Chronica. Kósmos, n. 1, jan. 1904.

BUCCI, E. Televisão objeto. 2002. Tese (Doutorado) - Escola de Comunicações e Artes, Universidade de São Paulo, São Paulo.

CANCLINI, N. G. Consumidores e cidadãos: conflitos multiculturais da globalização. Rio de Janeiro: Editora da UFRJ, 1995.

CUNHA, K. M. R. da. Entre Hermes e Poseidon: o jornalismo na teoria do acontecimento comunicacional. 2013. Tese (Doutorado em Ciências da Comunicação) - Escola de Comunicações e Artes, Universidade de São Paulo, São Paulo.

DEMENECK, Ben-Hur. Jornalismo transnacional: prática, método e conceito. 2016. Tese (Doutorado em Ciências da Comunicação) - Escola de Comunicações e Artes, Universidade de São Paulo, São Paulo.

FONSECA, E. G. da. O livro das citações. 2. ed. São Paulo: Companhia das Letras, 2008.

HEGEL, G. W. F. Aphorismen aus der Jenenser Zeit, no 31. In: HOFFMEISTER, J. (Org.)

Dokumente zu Hegels Entwicklung. 2. ed. Stuttgart: Frommann, 1974.

HUGO, V. Notre Dame de Paris. Disponível em: http://bit.ly/2fF6JuV. Acesso em: 20 nov. 2016.

KEHL, M. R. O fetichismo. In: SADER, E. (Org.). Sete pecados do capital. Rio de Janeiro: Record, 1999. p. 81-106.

KERCKHOVE, D. Foreword. In: MCLUHAN GALAXY CONFERENCE, Understanding Media, Today, Barcelona, 23-25 maio. Conference proceedings. Barcelona: Universidade Aberta da Catalunha, 2011.

MARX, K. O capital: crítica da economia política. Trad. Regis Barbosa e Flávio Koethe. 2. ed. São Paulo: Abril Cultural, 1985.

MIĖGE, B. L'espace public: perpétué, élargi et fragmenté. In: PAILLART, I. (Org.). L'espace public et l'emprise de la communication. Grenoble: Ellug, 1995. p. 163-175.

PETRY, A. Entenda o que é Big Data. Veja, 2321, 15 maio 2013, p. 71-81.

PULITZER, J. The School of Journalism in Columbia University. Nova York: The North American Review, 1904. Disponível em: http://bit.ly/2gPbk2R. Acesso em: 30 out. 2016.

REIS FILHO, D. A. O Manifesto Comunista 150 anos depois: Karl Marx, Friedrich Engels. Rio de Janeiro/São Paulo: Contraponto/Fundação Perseu Abramo, 1998.

ULLMAN, E. Big Data is watching you: "To save everything, click here", by Evgeny Morozov. The New York Times, 17 maio 2013. Disponível em: http://nyti.ms/1cXfee7. Acesso em: 20 nov. 2016

ZIZEK, S. O espectro da ideologia. In: . Um mapa da ideologia: Rio de Janeiro:

Contraponto, 1996. p. 7-38. 